Hydraulic Engineering Repository

Ein Service der Bundesanstalt für Wasserbau

Chiew, Yee-Meng; Narasimhan, Nandakumar; Chu, Jian

Effect of Seepage on River Bank Stability

Verfügbar unter / Available at:

https://hdl.handle.net/20.500.11970/100298

Vorgeschlagene Zitierweise / Suggested citation:

Chiew, Yee-Meng; Narasimhan, Nandakumar; Chu, Jian (2010): Effect of Seepage on River Bank Stability. In: Burns, Susan E.; Bhatia, Shobha K.; Avila, Catherine M. C.; Hunt, Beatrice E. (Hg.): Proceedings 5th International Conference on Scour and Erosion (ICSE-5), November 7-10, 2010, San Francisco, USA. Reston, Va.: American Society of Civil Engineers. S. 358-367. 


\section{Effect of Seepage on River Bank Stability}

\section{Yee-Meng Chiew ${ }^{1}$, Nandakumar Narasimhan ${ }^{2}$ and Jian $\mathrm{Chu}^{3}$}

${ }^{1}$ School of Civil and Environmental Engineering, Nanyang Technological University, Nanyang Avenue, Singapore 639798, PH: (+65) 6790-5256; e-mail: cymchiew@ntu.edu.sg

${ }^{2}$ School of Civil and Environmental Engineering, Nanyang Technological University, Nanyang Avenue, Singapore 639798

${ }^{3}$ School of Civil and Environmental Engineering, Nanyang Technological University, Nanyang Avenue, Singapore 639798, PH: (+65)6790-4563; cjchu@ntu.edu.sg

\section{ABSTRACT}

The collapse of river banks around the world has caused widespread damages to land and property. In many instances, human lives are lost as a result of such failures. A better understanding of the mechanism leading to river bank failure is necessary before engineers can arrive at a cost-effective countermeasure to prevent such a disaster. To this end, an experimental study was conducted in a laboratory flume to investigate the correlation between river bank stability and seepage under a unidirectional current. The study examined the collapse of a bank slope consisting of non-cohesive sediment with the channel and ground water flow as the only variables. The experiments were carried out on two bank slopes $=27$ and 20 degrees with the horizontal. While most studies hitherto have focused on the two variables independently (i.e., seepage and current effects separately), this study investigated their combined effect on failure of the bank slope. The dimensionless Reynolds number, which is a measure of shear stresses, is used as an indicator of erosion due to the main channel flow, while the critical hydraulic gradient is used to account for the onset of collapse. Moreover, the critical hydraulic gradient is also plotted as a function of the dimensionless seepage rate, which is the ratio of the applied shear velocity and the rate of drawdown, $\mathrm{u}_{*} /(\mathrm{dh} / \mathrm{dt})$. The results show that an increased in channel flow velocity (hence an increase in bed shear stresses) enhances slope failure, thereby causing it to collapse at a lower hydraulic gradient than that in a quiescent condition or with very low flow velocity. Additionally, the bank slope at 20 degrees requires a higher hydraulic gradient to initiatiate collapse as compared to its 27 degree counterpart with the same channel flow velocity. The study provides an improved understanding on slope failure in river channels, particularly for cases when there is a rapid drawdown of the flow stage during the recession period of the flood hydrograph.

\section{INTRODUCTION}

The collapse of river banks can cause widespread damages to land and property. This is particularly relevant to agrarian societies such as China and India. Figure 1(a) shows the collapse of a 6-m high bank along the Han River in China. Figure 1(b) shows the collapse of a bank along Yangtze River in Hubei Province (Xinhua News Agency, 2008), China while Fig. 1(c) shows how houses fell into the 
river as a result of failure of a bank along the Mekong River in Vietnam. All these examples reveal the importance in providing cost-effective engineering solutions to prevent a loss of lives and properties associated with river bank failures.

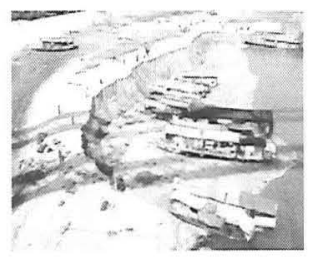

Figure 1(a): Collapse of a 6-m high river bank along Han River. Area affected $>100 \mathrm{~m} \times 20 \mathrm{~m}$

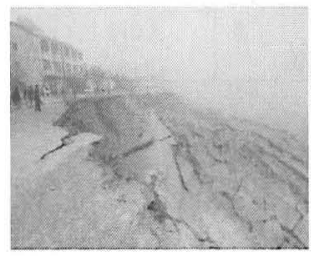

Figure 1(b): Collapse of a river bank along Yangtse River, China, 2008.

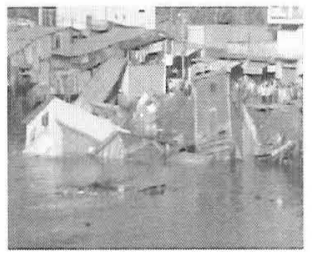

Figure 1(c): Collapse of a river bank along Mekong River, Vietnam

The movement of groundwater through porous river banks makes it an important parameter when analysing the stability of a channel. While groundwater flow alone sometimes may not significantly contribute to the displacement of sediments under certain conditions, it could become important when combined with flows in the river. To this end, experiments are performed to examine how the governing variables e.g., velocity of flow, hydraulic gradient etc. would affect river bank stability.

While fluvial erosion under seepage has been the subject of some studies, e.g., Cheng and Chiew (1999), Rao and Nagraj (1999), etc., few studies have been devoted to the study of river banks failure with seepage under a unidirectional flow. The bulk of available research focuses on the incipient motion or entrainment of sediments rather than the collapse of the entire bank. Geotechnical papers on slope stability, e.g., Hight et al. (1999), Hunt (2007), and Michalowski \& Viratjandr (2006), do not account for channel flow hence fluvial erosion is neglected in these studies. In view of this limitation, the objective of this paper aims to investigate the combined effect of seepage and main flow velocity on river bank stability in order to provide an improved understanding on this topic.

\section{EXPERIMENTAL SETUP AND METHODOLOGY}

The experiments were conducted in a laboratory flume that was $7 \mathrm{~m}$ long, 1.6 $\mathrm{m}$ wide and $0.6 \mathrm{~m}$ deep. The flume, which is shown in Fig. 2, had been modified to accommodate the river bank and the accompanied seepage unit to effect groundwater flow. The plan view of the modified flume together with the dimensions is shown in Fig. 2(a), while the test section is shown in Fig. 2(b). Water enters the flume through a perforated barrier so as to smoothen the flow in the channel. The flow depth is controlled by using a tail gate at the downstream end of the flume. 

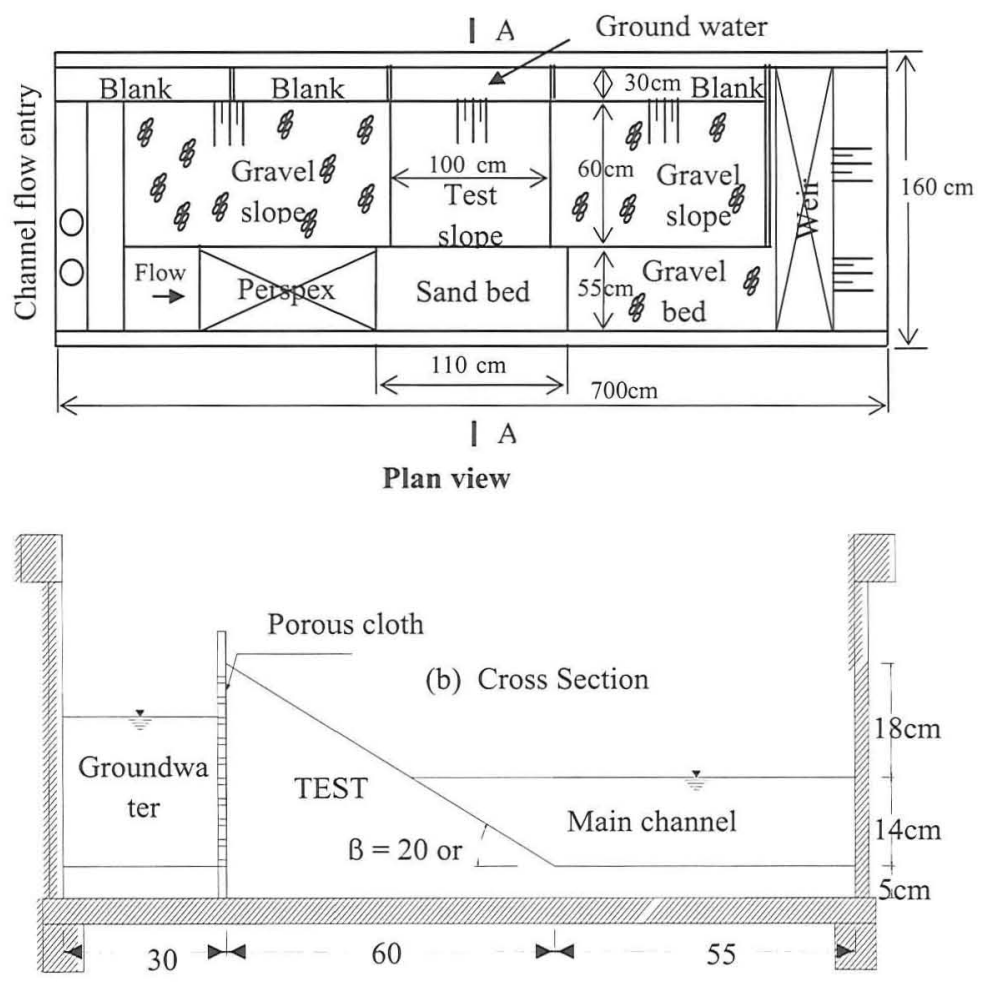

Elevation View

Figure 2: Experimental flume set-up (a) Plan view; (b) Elevation (A-A) View

The length of the test section is $1 \mathrm{~m}$, in which uniformly distributed sand with a median grain size, $\mathrm{d}_{50}=0.2 \mathrm{~mm}$ was placed. Two different bank slopes $=20^{\circ}$ and $27^{\circ}$ were tested in the study. The test section is located about 3 meters from the entrance to the flume. This is to allow for stabilisation before the flow reaches the test section. The portion of the flume upstream and downstream of the test section is lined with gravel so as to minimise disturbances often encountered when flowing water moves from one surface to another. Another transitional surface was introduced upstream of the sand bed. This consisted of a Perspex sheet with the same sand grains glued on its top (see Fig. 2a). The seepage section comprises a 1-m long 
perforated Perspex sheet with 2-cm diameter holes at $5 \mathrm{~cm}$ intervals throughout its length and up to a height of $30 \mathrm{~cm}$. This sheet is covered with a cloth so as to ensure uniform seepage.

\section{Experimental Procedure}

Preliminary tests were conducted with the intention of getting certain basic properties of the bed sediment used in the study. This includes a constant head permeability test and sieve analysis to determine the coefficient of permeability and grain size distribution of the bed sediment, respectively. Moreover, the angle of repose of the sediment also was determined using the standard test whereby loose dry sand was dropped from a height of $20 \mathrm{~cm}$. The resulting slump angle was calculated using simple trigonometric ratios from the measured dimensions of the sediment heap. Table 1 summarizes the basic properties of the bed sediment used in the study. The results so-obtained show that the bed sediment is a poorly-graded fine sand, with a median grain size of $0.2 \mathrm{~mm}$.

Table 1. Property of sediment used in study

\begin{tabular}{c|c|c|c}
\hline $\begin{array}{c}\text { Median grain } \\
\text { size, } \mathrm{d}_{50}(\mathrm{~mm})\end{array}$ & $\begin{array}{c}\text { Uniformity } \\
\text { Coefficient }\end{array}$ & $\begin{array}{c}\text { Angle of } \\
\text { repose }\end{array}$ & $\begin{array}{c}\text { Coefficient of } \\
\text { Permeability }(\mathrm{m} / \mathrm{s})\end{array}$ \\
\hline 0.2 & 1.29 & 29.7 & $5.47 \times 10^{-4}$ \\
\hline
\end{tabular}

The following tests procedure was adopted for all the tests in the study:

(a) Water is slowly pumped into the flume and the groundwater reservoir using 2 different hydraulic machines until the pre-determined steady state is reached, which is identified as the condition where the water levels in the main channel and groundwater reservoir are the same.

(b) Additional water is pumped into the groundwater reservoir at different rates to introduce a head difference, causing seepage through the test slope.

(c) The rate of increase of water level in the groundwater reservoir is quantified as $\mathrm{dh} / \mathrm{dt}$.

(d) The groundwater level is carefully monitored throughout the experiment, particularly to record the time taken for the river bank just to collapse. This constitutes the onset of critical failure of the slope.

(e) The experiment is repeated with different flow velocities in the main channel. For each undisturbed mean velocity, $U_{0}$, the experiment is repeated 5 times with the same $\mathrm{dh} / \mathrm{dt}$ in order to ensure consistency.

(f) The hydraulic gradient at the onset of collapse is calculated using the flow net diagram as described in Harr (1962). This is the measured critical hydraulic gradient, $i_{c}$.

(g) Using the measured data, a correlation between the critical hydraulic gradient, $\mathrm{i}_{\mathrm{c}}$ and the particle Reynolds number, $\mathrm{Re}_{*}\left(=\mathrm{u} * \mathrm{~d}_{50} / v\right)$ is prepared. The critical hydraulic gradient is also plotted against a dimensionless 
seepage rate, $\mathrm{u}_{*} /\{\mathrm{dh} / \mathrm{dt}\}$ in order to examine the effect of drawdown on the stability of the slope.

(h) The bed shear velocities of the tests were determined using the velocity profile obtained by measuring the flow velocities at various depths. The values for the shear velocity, $\mathrm{u} *$ were calculate using the mean velocity equation for a rough bed.

$$
\frac{U_{o}}{u_{*}}=5.75 \log \frac{y_{o}}{k_{s}}+6
$$

where $\mathrm{U}_{\mathrm{o}}=$ undisturbed mean velocity in the main channel; $\mathrm{u}_{*}=$ shear velocity; $\mathrm{y}_{\mathrm{o}}=$ flow depth; and $\mathrm{k}_{\mathrm{s}}=$ bed roughness height.

\section{BANK SLOPE FAILURE MECHANISM}

In order to examine how the threshold of bank slope failure is related to the applied shear stresses in the main channel and seepage flow through the bank, one needs to have a precise definition of what this constitutes. In general, bank slope failure is identified by the appearance of deformation on the surface of the test section. To this end, the entire failure process, which is documented in a series of photographs in Fig. 3, can be classified into three different stages. The first stage, which is the critical failure stage, constitutes the onset of collapse and the accompanying localized downward movement of the sand particles on the slope (Fig. 3b). Advanced failure, which leads to a larger mass of sand movement and a "slurry" of debris flow is shown in Figs. 3(c), (d) and (e). At this (second) stage, failure cracks begin to propagate sideways along the bank. With time, the cracks slowly propagate upward along the slope, causing further instability. The complete collapse of the slope is shown in Fig. 3(f). At this final stage no further observable movement of the slope occurs; the water levels in the groundwater reservoir and main channel are the same again.

Figure 4 shows the total collapsed bank slope after water is completely drained from both the main channel and groundwater reservoir. It also shows an enlarged view of a particular section of the failed slope. Moreover, a ruler is superimposed in the figure to provide the magnitude of the extent of the collapsed slope. While the onset of bank slope failure (Fig. 3b) could be sudden, the transition from the first to the third stage is gradual and uncertain.

In order to avoid ambiguity, the critical failure shown in Fig. 3(b) is used as the benchmark for all experiments for further analyses. This failure type is a flow slide which is typical of submerged sandy slopes and is similar to what has been described in Hight et al (1999). 
Water surfuee level at burk
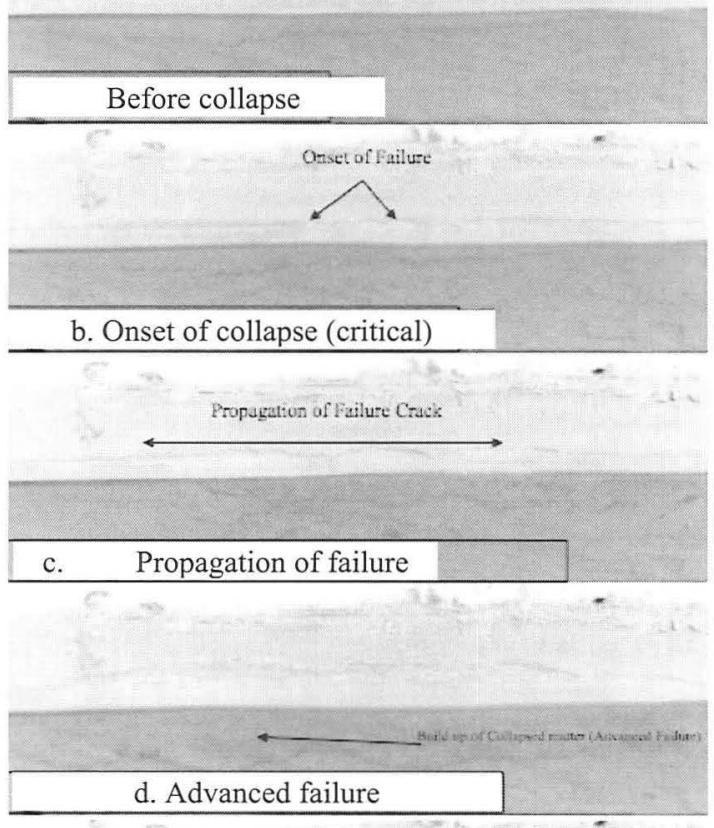

Upward Propagation of Fialure Cack

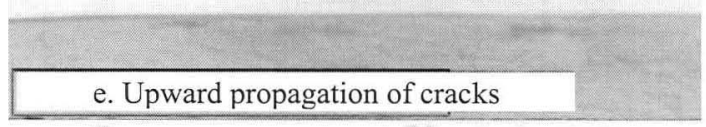

f. Complete collapse of bank slope

Figure 3: Failure process of experimental slope 


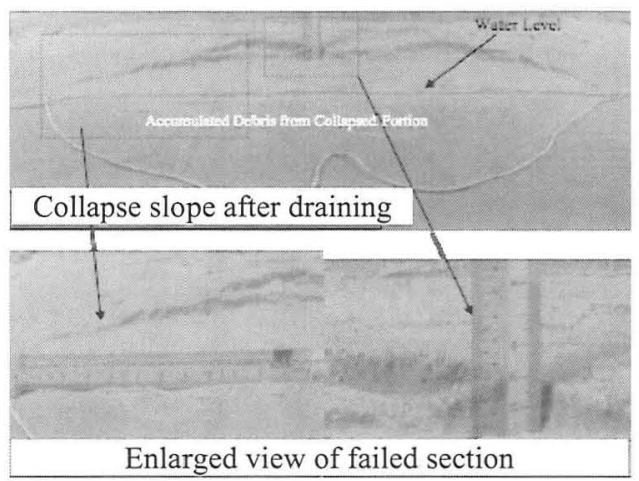

Figure 4 Collapsed portions of bank slope

\section{RESULTS ANDS DISCUSSION}

Figure 5 shows the plot of the measured critical hydraulic gradient, $\mathrm{i}_{\mathrm{c}}$ as a function of the particle Reynolds number, $\mathrm{Re}_{*}$. It reveals a marked difference in the critical hydraulic gradient for the onset of collapse of the two different bank slopes. While the 27-degree slope fails at a critical hydraulic gradient of 0.331 at $U_{0}=0$, the 20 -degree slope does so at a significantly higher value of 0.463 . This can be attributed to the proximity to the angle of repose of the 1:2 slope (27 degrees), which causes the slope to become unstable, even at low hydraulic gradients.

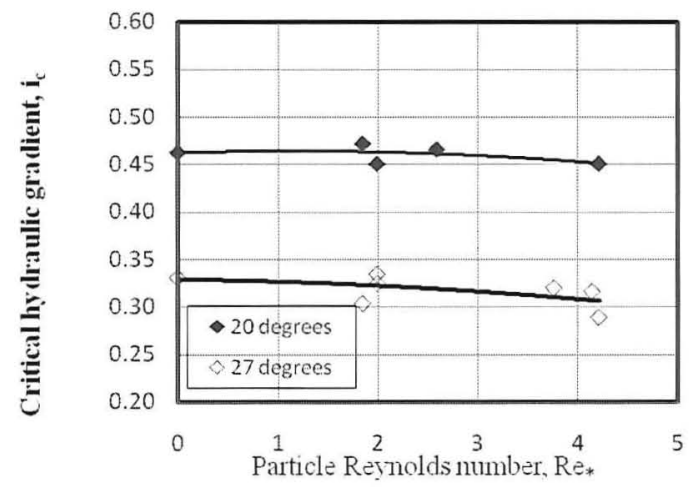

Figure 5. Effect of particle Reynolds number, $\mathrm{Re}_{*}$ on critical hydraulic gradient, $i_{c}$ 
At higher main channel flow velocities, the data show a small reduction in the hydraulic gradients required for the onset of collapse. This is due to the increased channel flow velocity that causes the sand on the surface of the slope to be eroded, thus facilitating the collapse. The fact that sediment particles on the bank is already in motion is supported by the computed bed shear velocity in that location, which is found to be well above the critical shear stress required for the initiation of motion calculated using the Shields diagram (Shields, 1936). Moreover, small sand dunes were observed at the base of the slope indicating that the sediment particles are already in motion.

An additional parameter, namely, the seepage rate, $\mathrm{dh} / \mathrm{dt}$ is known to have an important effect on the pore water pressure distributions and thus hydraulic gradients in the soil in the slope. When $\mathrm{dh} / \mathrm{dt}$ is higher, the pore water pressure builds up in the soil because of its inability to dissipate the pore pressure quickly enough. To examine how this may affect bank slope stability, a dimensionless seepage rate is proposed as a first approximation, and the measured data fitted to examine its effect on the critical hydraulic gradient, $\mathrm{i}_{\mathrm{c}}$. To this end, the plot of the measured critical hydraulic gradient as a function of the dimensionless seepage rate, $\mathrm{u} * /\{\mathrm{dh} / \mathrm{dt}\}$ is plotted in Fig. 6 . Here, the dimensionless seepage parameter is used to quantify the relative magnitude of the applied shear stress on the bed and the rate at which pore water pressure is dissipated. The experimental data show that a higher dimensionless seepage rate leads to lower critical hydraulic gradient, i.e., that it is easier for a slope to fail for a higher $\mathrm{u} * /\{\mathrm{dh} / \mathrm{dt}\}$, even though the effect does not appear to be large. One may infer from the data to mean that an increased bed shear stress or a reduction in $\mathrm{dh} / \mathrm{dt}$ will lead to a reduced critical hydraulic gradient. The results in this series of test support those summarized in Fig. 5 that the undisturbed applied shear stress on the main channel has an effect on the overall stability of the river bank.

As observed in the experiments and other case histories (Hight et al. 1999), slopes fail in a series of slides. It normally initiates from the toe and then propagates upward. Another effect of the river flow is the removal of debris of the first slide at the toe in the form of a scour. The debris plays a stabilizing effect on the slope. Once it is removed, it will cause the slope to be less stability and lead to the occurrence of subsequent slides, as demonstrated by Leong et al (2001), and to a certain extent, illustrated in Fig. 3. It may be surmised that the faster the river flow, the greater the ability for the debris to be removed and the faster the rate of removal. Therefore, the flow rate of the river and its turbulence will also affect the stability of slope. 


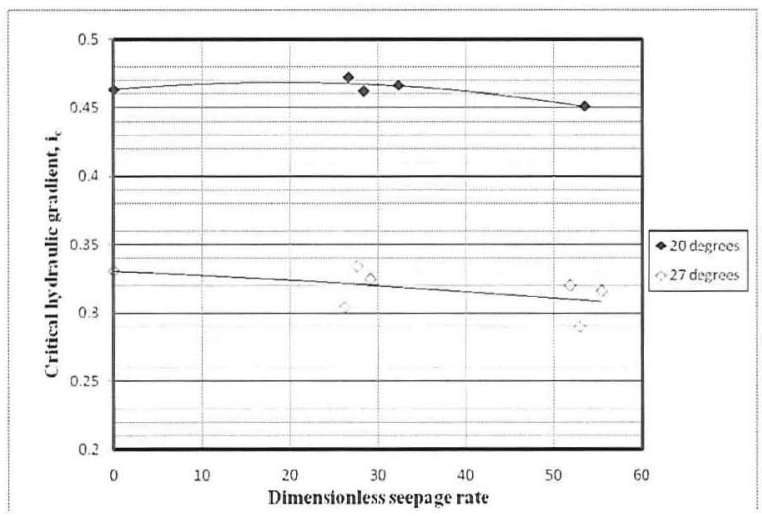

Figure 6. Effect of dimensionless seepage rate, $\mathrm{u} * /(\mathrm{dh} / \mathrm{dt})$ on critical hydraulic gradient, $i_{\mathrm{c}}$

\section{CONCLUSIONS}

The following conclusions are drawn based on the experiments of a 27- and 20-degree bank slope consisting of non-cohesive sediment with a uniform grain size distribution and median diameter of $0.2 \mathrm{~mm}$

1. The 27-degree bank slope undergoes failure at a significantly lower hydraulic gradient as compared to the 20-degree bank slope for the same undisturbed main flow velocities.

2. The hydraulic gradient needed to just initiate bank failure is not only related to the seepage flow through the bank, but also the particle Reynolds number.

3. The critical hydraulic gradient for a given bank slope is lower for a higher particle Reynolds number.

4. The critical hydraulic gradient for a given bank slope is lower for a higher dimensionless seepage rate. 


\section{ACKNOWLEGEMENT}

The authors acknowledge the support from DHI-NTU Water \& Environment Research Center and Education Hub.

\section{REFERENCES}

Cheng, N. S. and Chiew Y. M. (1999). "Incipient Motion with Upward Seepage", $J$ Hydraulic Research, IAHR, 37(5): 665- 681.

Harr, M. E. (1962), Groundwater adn Seepage, Mcgraw Hill, New York.

Hight, D. W., Geogiannou, V. N., Martin, P. L., and Mundegar, A. K. (1999). "Flow slides in micaceous sands." Problematic Soils, Yanagisawa, Moroto, and Mitachi, eds. Balkema, Rotterdam, The Netherlands: 945-958.

Hunt, R. E. (2007). "Geotechnical Engineering Investigation Handbook: 2nd E dition", Taylor and Francis Group, CRC Publication.

Leong, W. K., Chu, J., and Hight, D. W. (2001). "Slip failures in granular slopes: some observations from model tests." Proc. 14th Southeast Asian Geotechnical Conference, 10-14 Dec, Vol. 1, Hong Kong: 819-824.

Michalowski. R. L. and Viratjandr, C. (2006), "Limit Analysis of Submerged Slopes Subjected to Water Drawdown" Canadian Geotech. J. 43(8): 802- 814.

Rao, R. A. and Nagraj, S. (1999), "Stability and Mobility of Sand Bed Channels affected by Seepage" J. of Irrigation and Drainage Engrg., 125(6): 370- 379.

Sheilds, A., (1936), Anwendung der Aehnlichkeitsmechanik und der Turbulenzforschung auf die Geschiebebewegung, Mitt. Preuss. Versuchsanst. Wasserbau Schiffbau, (English translation by W. P. Ott and J. C. van Uchelen, 36 pp., U.S. Dep. of Agric. Soil Conser. Serv. Coop. Lab., Calif., Inst. of Technol., Pasadena, 1936).

Xinhua News Agency (2008), "Unstable Geology Triggers River Bank Collapse" Retrieved 13th September 2008 from China.org.cn. Website: http://www.china.org.cn/environment/news/2008-04/08/content 14512247.htm 